\title{
ON THE ASYMPTOTIC BEHAVIOR AND APPROXIMATE SOLUTIONS OF VARICELLA ZOSTER VIRUS MODEL USING MODIFIED DIFFERENTIAL TRANSFORM METHOD
}

\author{
Oluwatayo Ogunmiloro ${ }^{1,2}$ \\ ${ }^{1}$ Ekiti State University \\ ${ }^{2}$ Ekiti State University Faculty of Science
}

September 10, 2020

\begin{abstract}
This article proposes a mathematical model describing the evolution and transmission of Varicella Zoster Virus (VZV) over large groups of individuals. The model was formulated to accommodate parameters and variables describing direct and indirect forms of transmission, re-activation of infectious shingles as well as treatment and vaccination of susceptible births and influx of immigrants. The model was analysed to be positive, bounded and well posed. The controlled basic reproduction number Rvzv, obtained using the next generation matrix operator reveal that vaccination is effective as a control in creating a level herd immunity. Linearizing the model around the VZV - free equilibrium shows that the model is locally and globally asymptotically stable when Rvzv is less than unity. The approximate solutions of the model system equations was obtained using the modified differential transform which involves the Differential Transform Method (DTM) and Laplace - Pade post-treatment technique (LPDTM). This technique was employed to enlarge the domain of convergence of the approximate solutions of the model. LPDTM was compared with the Fehlberg fourth order Runge - Kutta (RKF45) via the MAPLE computational software to show the accuracy of the results through simulations. Further simulations carried out on the model reveal that timely vaccination and treatment are eeffective strategies in containing VZV infection spread in human and environmental host population.
\end{abstract}

\section{Hosted file}

article-vzv.pdf available at https://authorea.com/users/342685/articles/480238-on-theasymptotic-behavior-and-approximate-solutions-of-varicella-zoster-virus-model-usingmodified-differential-transform-method 